\title{
Mediterranean Holocene climate and human societies
}

\author{
Karin Holmgren', M.-A. Sicre ${ }^{2}$, A. Gogou ${ }^{3}$, E. Xoplaki ${ }^{4}$ and J. Luterbacher ${ }^{4}$ \\ Messinia, Greece, 23-25 April 2014
}

Holocene climate reveals notable changes in the Mediterranean region (e.g. Finné et al. 2011; Roberts et al. 2011). The region also bears a long history of human society dynamics, making it a suitable site for exploring interactions between climate, environment and humans over a variety of time scales (e.g. Weiss 2012; Walsh 2013; Kaniewski et al. 2013). A workshop addressing these issues took place at the Navarino Environmental Observatory (NEO), Costa Navarino, Greece. Sixty-one participants from a total of 16 countries attended. They represented a range of disciplines, including history, archeology, paleoclimatology, hydrology and modeling.

On the first half-day keynotes were presented on proxy records and important archeological and historical topics addressing the dynamics of past societies. The rest of the workshop was devoted exclusively to discussions. The participants broke out into chaired groups, with representatives from all disciplines, to critically discuss common themes on the interrelation between climate, environment and human societies. One of the key issues emphasized by the workshop participants was that although current global warming has inspired scientists to look back into the past, when trying to explore the connection between climate change and societal changes from a historical perspective, many limitations still remain. For example, links are often inferred using poorly dated "parallels" between cultural and climate changes; these chronological issues need to be better addressed. Moreover, the fact that two events happen at the same time does not permit conclusions to be drawn regarding causation; it is critical to understand the driving processes behind potential correlations. Equal attention should be paid to other, non-climatic, factors also affecting societies, e.g. political, economic and social structures.

The workshop participants recommended that future research in this area should include the full and equal participation of archeologists, historians and climate researchers throughout the entire process, from the project design stage to execution of research. This approach would enable the development of truly integrated research programs, conceptual models and local case studies, and overcome the barriers that might be perceived due to different scientific traditions, theories, methods and languages. Instead of being hindered by these perceived barriers, we should take advantage of, and use the diverse expertise we have to explore how we can generate new knowledge and pose new hypotheses and questions that may not yet have been asked. One way forward could be to focus on certain periods and areas

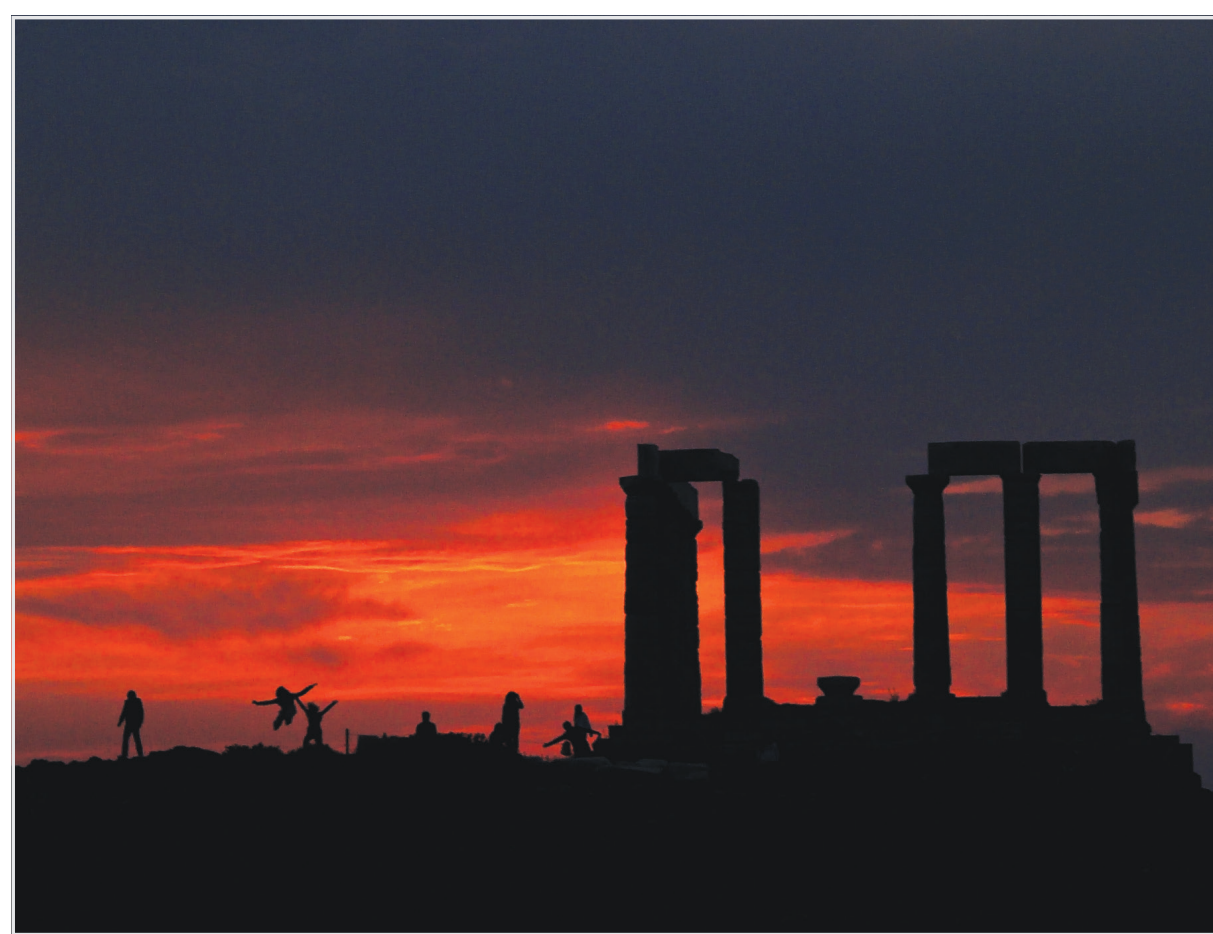

Figure 1: Having the workshop in Greece - a country rich in archeology, history and social dynamics - inspired the participants in their creative discussions on climate, environment, people and their societies. Photo: Poseidon Temple in Cape Sounion, Attica Peninsula (by Nikolas Lambrou).

with high data density (e.g. a specific climate event or a specific time containing substantial social transitions), and explore the evidence from different disciplines, critically evaluating the consistencies and connections, and addressing the role of different forcing factors. Another approach could be to look not only for climate change and societal "collapses", but to seek "success" stories and explore key factors behind resilient societies.

Allocating enough time for discussions in interdisciplinary groups was key to breaking down some of the barriers between the scientists of different backgrounds, and inspired many to begin planning joint research initiatives. One first step in this direction will be to publish papers on the workshop theme in a special issue of Quaternary Science Reviews. The proposed 15-20 contributions to this forthcoming issue will include synthetic papers, conceptual papers and local case studies, and will be written jointly by researchers from different disciplines. Another step is to develop the proposed idea of organizing Navarino Summer Schools and Navarino Workshops, each on a biannual basis, for improving communication between communities and to develop methodologies that work towards fully integrated conceptual models that incorporate all signals, including human behavior in a common chronological framework.

\section{ACKNOWLEDGEMENTS}

The workshop was co-sponsored by PAGES, NEO, the MISTRALS/ PaleoMex program, the Labex OT-Med, the Bolin Centre for Climate Research at Stockholm University, and the Institute of Oceanography at the Hellenic Centre for Marine Research.

\section{AFFILIATIONS}

${ }^{1}$ Navarino Environmental Observatory (NEO) and Bolin Centre for Climate Research, Stockholm University, Sweden

'LOCEAN, Sorbonne University, Paris, France ${ }^{3}$ Institute of Oceanography, Hellenic Centre for Marine Research, Anavyssos, Greece

${ }^{4}$ Department of Geography, Justus-Liebig University Giessen, Germany

\section{CONTACT}

Karin Holmgren: Karin.holmgren@natgeo.su.se

\section{REFERENCES}

Finné M et al. (2011) J Archaeol Sci 38: 3153-3173

Kaniewski D et al. (2013) PLOS ONE 8, doi:10.1371/journal. pone.0071004

Roberts N et al. (2011) Holocene 21: 147-162

Walsh K (2013) The archaeology of mediterranean land scapes. Cambridge University Press, 384pp

Weiss H (2012) In: Weiss H (Ed) Seven generations since the fall of Akkad. Harrassowitz, 1-24 